\title{
Pharmacy Awareness: A Continuous Process
}

\author{
Bruce Millin
}

$\mathrm{I}^{2}$ am writing this report just before the start of another Pharmacy Awareness Month (PAM). PAM is an excellent opportunity to raise awareness of pharmacy's impact on patients. It also gives organizations and individual practitioners the chance to highlight pharmacists as the medication experts in our health care system. This year's campaign comes at an opportune time, given recent media coverage (driven by a CBC Marketplace investigative report) calling into question pharmacy practice and care. Although the Marketplace report did not focus on pharmacy practice in an institutional health care setting, it did tarnish the image of pharmacists and the vital role they play in ensuring that patients receive safe and effective medication therapy. It would be easy to dismiss the report as not being relevant to hospital practice or to get defensive about the findings and point out the flaws in the investigation. However, I think we should recognize the report for what it said and see it as an opportunity to highlight the systems and the checks and balances currently in place to identify, resolve, and prevent drug therapy problems.

While PAM provides opportunities to raise the profile of the pharmacist, we should not lose sight of the fact that advocating about our role is a continual process. Throughout 2015 and beyond, the Canadian Society of Hospital Pharmacists (CSHP) will continue to demonstrate its leadership in contributing to high-quality patient safety and care. Staples of this effort include practice excellence initiatives such as CSHP 2015, promotion of the CSHP advocacy tool kit, and ongoing collaboration with organizations such as Health Canada, the National Association of Pharmacy Regulatory Authorities, the Canadian Pharmacists Association, the Canadian Association of Pharmacy in Oncology, the Association des pharmaciens des établissements de santé du Québec, the Canadian Patient Safety Institute, the Institute for Safe Medication Practices

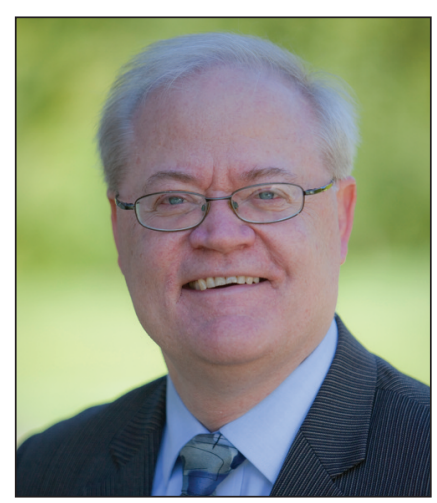
Canada, and the Canadian Association of Pharmacy Technicians.

CSHP's advocacy efforts at both the National and Branch levels are necessary and appropriate, but advocacy at the grassroots level is crucial. At the front line, dealing with the daily workload and patient care demands, individual practitioners often find it difficult to see how they personally can be advocates for change and for the profession. I would invite you to consider the possibility that each and every interaction that a pharmacist has with either a health care professional or a patient is a moment of advocacy, not just for the profession, but also for the patient. What a powerful combination.

Bruce Millin, BSc(Pharm), ACPR, is President and Internal Liaison for the Canadian Society of Hospital Pharmacists. 